Investigaciones Feministas

ISSN-e: 2171-6080

http://dx.doi.org/10.5209/INFE.57199

\title{
La prostitución en el corazón del capitalismo
}

\author{
Beatriz Ranea Triviño ${ }^{1}$
}

Rosa Cobo, Editorial Los Libros de la La Catarata, Madrid, 2017, 213 páginas. ISBN: 978-84-9097-326-4

Rosa Cobo presenta en La prostitución en el corazón del capitalismo un análisis de gran profundidad sobre el rol que juega la prostitución en las sociedades contemporáneas. Para ello, la autora nos acerca a las transformaciones que se han producido en las últimas décadas, que sitúan la prostitución en la intersección de tres sistemas de dominación: el patriarcal, el capitalista neoliberal y el racial/cultural. En este sentido, el libro sigue y completa el camino abierto por autores/as como Sheyla Jeffreys (2009) o Richard Poulin (2011) señalando que el origen patriarcal de la prostitución ha de ser inscrito en las lógicas de la globalización del capitalismo neoliberal, para comprender el surgimiento y expansión de la macroindustria de la prostitución, que se conoce como "industria del sexo". Por ello, la prostitución ha de analizarse desde la economía política para comprender el poder que adquiere como sector económico (vinculado a la economía criminal) en muchos países.

Además, el libro nos introduce en los ejes que atraviesan y configuran el sistema prostitucional. Entre ellos, la autora destaca la centralidad de la noción patriarcal de las mujeres como mero cuerpo sin individualidad, como la condición necesaria para convertirlas en "idénticas" (Amorós, 1987) y con ello, en bienes intercambiables en el mercado de la prostitución. A través de la genealogía feminista, Cobo destaca la importancia del feminismo radical de los años sesenta y setenta, pues sus vindicaciones emancipatorias buscaban escapar de las definiciones patriarcales que construyen los cuerpos femeninos como cuerpos subalternos sobrecargados de sexualidad para satisfacer la mirada masculina heterosexual. Como contragolpe al feminismo radical, emerge lo que la autora denomina "reacción patriarcal", fuertemente relacionada con el crecimiento de la prostitución. Para dar cuenta de ello, la autora retoma a Carole Pateman (1995) y la herramienta teórica del contrato sexual, explicando como la quiebra de una parte del contrato sexual ha provocado un reforzamiento de la otra. Es decir, el contrato sexual se articula sobre el reparto de las mujeres en dos instituciones fundamentalmente: de un lado, el matrimonio donde las mujeres son propiedad de un solo varón; y de otro, la prostitución donde las mujeres son propiedad colectiva de todos los hombres. Con el avance de las demandas feministas, una de las partes del contrato sexual comienza a quebrarse, y como Cobo (2017:203) afirma "a medida que algunas mujeres pueden desasirse del dominio masculino y conquistan parcelas de individualidad y autonomía, otras son más intensamente dominadas y explotadas por el sistema patriarcal" en escenarios como el prostitucional.

Universidad Complutense

b.ranea@ucm.es 
Por otro lado, la autora realiza un análisis sobre la mundialización de la pornografía conocida como hegemónica o mainstream. Ésta presenta contenidos de carácter patriarcal y no solo produce la hipersexualización de las mujeres, sino que en ella encontramos múltiples expresiones de violencia. Además, para acercarnos con rigor a este fenómeno, Rosa Cobo señala la importancia de la industria de la pornografía, cuya expansión la convierte en un fenómeno de masas, que ha dado lugar a la pornificación de la cultura y que sitúa a la pornografía como un dispositivo de socialización. Es decir, la pornografía constituye hoy en día un elemento fundamental de (des)educación sexual de los jóvenes. Y el imaginario sexual pornográfico puede ser considerado como pedagogía de la prostitución porque el modelo de sexualidad androcéntrico y patriarcal que se aprende encuentra en la prostitución un espacio para recrearse.

Asimismo, el libro aborda la trata de mujeres y niñas con fines de explotación sexual, fenómeno que actualmente ha alcanzado una magnitud sin precedentes como instrumento para nutrir esa industria de la prostitución que necesita renovar la "oferta" de mujeres de forma constante. Por esto, la trata no puede ser obviada en el análisis de la prostitución y la autora interpela a aquellos/as autores/as que se refieren al "mito trafiquista", y se ubican en una especie de negacionismo de la trata ocultando las múltiples violencias que sufren las víctimas.

En este sentido, hay puntos de vista que tratan de despolitizar el análisis de la prostitución y la trata, y evitan situar este fenómeno dentro del entramado sociocultural y económico en el que se produce. Para despolitizar la prostitución, como señala Cobo, las sociedades producen relatos que naturalizan instituciones sociales y nos encontramos con mitos que transitan entre el cliché del oficio más antiguo del mundo hasta la ontologización de la sexualidad masculina como impulso irrefrenable. En referencia la sexualidad masculina, la autora concluye el libro con un análisis imprescindible sobre la construcción de la masculinidad en relación al consumo de prostitución en los patriarcados contemporáneos. De esta forma, es de especial relevancia el análisis de la reacción patriarcal a través de la cual se reconfigura la prostitución como uno de los escenarios más paradigmáticos donde los hombres pueden representar el poder de la masculinidad hegemónica sin ser interpelados críticamente. Como afirma Rosa Cobo, la fractura de la subjetividad masculina que se ha producido ante la quiebra de algunos de los pilares sobre los que se sostenía la masculinidad tradicional — como, por ejemplo, el rol de proveedor o la crisis familia patriarcal - dotan a los espacios de prostitución de una importancia central en la recomposición de la identidad masculina patriarcal. Por último, un aporte fundamental de la autora es conceptualizar a los hombres prostituidores como los nuevos bárbaros del patriarcado.

Por todo lo expuesto, Rosa Cobo ha elaborado en La prostitución en el corazón del capitalismo un texto de referencia no solo para la sociología y el estudio de la prostitución sino para el pensamiento crítico feminista.

\section{Referencias bibliográficas}

Amorós, Celia (1987): “Espacio de los iguales, espacio de las idénticas. Notas sobre poder y principio de individuación" Arbor: Ciencia, pensamiento y cultura 503-504 pp. 113-128 
Jeffreys, Sheyla (2009): The Industrial Vagina. The Political Economy of the Global Sex Trade. Nueva York: Routledge.

Pateman, Carole (1995): El contrato sexual. Barcelona: Anthropos.

Poulin, Richard (2011): La Mondialisation des Industries du sexe. París: Imago. 